\title{
Selected clinical highlights from the 2010 ERS Congress in Barcelona
}

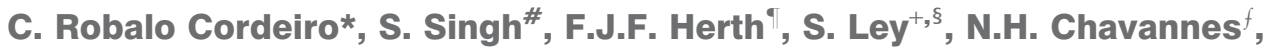 \\ E. Clini** and V. Cottin ${ }^{\# \#, 9 \uparrow}$
}

ABSTRACT: This article reviews a selection of presentations at the 2010 annual meeting of the European Respiratory Society held in Barcelona, Spain, which was the largest congress ever in the field of respiratory medicine. The best abstracts from the groups of the Clinical Assembly (Clinical Problems, Rehabilitation and Chronic Care, Imaging, Interventional Pulmonology, Diffuse Parenchymal Lung Disease, and General Practice and Primary Care) are presented in the context of the current literature.

KEYWORDS: Interstitial lung disease, interventional pneumology, lymphangioleiomyomatosis, pulmonary fibrosis, pulmonary hypertension, rehabilitation

$\mathrm{T}$ he 2010 European Respiratory Society (ERS) Congress was held in Barcelona, Spain, September 18-22, 2010. The largest congress ever in the field of respiratory medicine featured a large programme that included original scientific presentations with published abstracts and many symposia devoted to synthetic presentation of medical literature and experience. Herein, an overview of the abstracts of the Clinical Assembly based on scientific merit, novelty and relevance are reported. Due to space constraints, only a selection in the field of the six scientific groups of this Assembly can be presented. They cover the spectrum of clinical problems, rehabilitation and chronic care, imaging of the lung, interventional pulmonology, diffuse parenchymal lung disease, and general practice and primary care.

\section{INTERVENTIONAL PULMONOLOGY}

Endoscopic interventions for chronic obstructive pulmonary disease (COPD) and emphysema were one of the major topics at the ERS Congress 2010. The development of minimally invasive methods to achieve lung volume reduction has been attempted with the aim of reduced morbidity compared with usual surgery. Lobe volume reduction with subsequent improvement of lung mechanics leads to decreased breathlessness on exertion and increased exercise capacity. Several techniques of lung volume reduction have been evaluated that may extend the therapeutic approach in patients with severe emphysema.

\section{Blocking devices}

Currently, the most successful method of endoscopic lung volume reduction in patients with heterogeneous emphysema is the implantation of endobronchial valves (Zephyræ; Pulmonx Inc., Palo Alto, CA, USA) or intrabronchial valves (Spiration ${ }_{\circledR}$; Olympus America Inc., Center Valley, PA, USA), targeting the lung compartments with the most advanced lesions [1]. These blocking devices vary in shape but both consist of a one-way valve that allows the air to exit during expiration but not to enter during inspiration, therefore causing lobar or segmental atelectasis and consequent volume reduction.

Identification of the candidate lobes to be treated is the key to success. High-resolution computed tomography (HRCT) and lung perfusion scan are then used in most centres before implantation of intrabronchial valves via flexible bronchoscope. One study has shown that single photon emission computed tomography (CT) may also be helpful to determine which lung lobes have the poorest perfused compartment [2].

The effect of endoscopic lung volume reduction surgery on lung perfusion, pulmonary function, dyspnoea and quality of life are being evaluated by several groups. In several pilot studies performing bilateral partial occlusion of both upper lobes in patients with upper lobe predominant emphysema, improvement was obtained in health-related quality of life and in regional lung volume changes, as measured by quantitative

\section{AFFILIATIONS}

*Dept of Pulmonology, Coimbra University Hospital, Research Centre of Pulmonology, Coimbra University, Coimbra, Portugal.

"Pulmonary Rehabilitation, Dept of Respiratory Medicine, University Hospitals of Leicester NHS Trust, Leicester, UK.

"Dept of Pulmonary and Critical Care Medicine, University of Heidelberg. +Dept of Diagnostic and Interventional Radiology, University of Heidelberg, Heidelberg, Germany. ${ }^{\S}$ Dept of Medical Imaging, University of Toronto, Toronto, ON, Canada. ${ }^{f}$ Dept of Public Health and Primary Care, Leiden University Medical Center, Leiden, the Netherlands. ${ }^{* *}$ DAl Oncology Haematology and Respiratory Diseases - Ospedale Villa Pineta, University of ModenaReggio Emilia, Modena, Italy. \#\#Hospices Civils de Lyon, Hôpital Louis Pradel, Centre national de référence des maladies pulmonaires rares, and

"Université de Lyon, Université Lyon I, INRA, UMR754 INRAVetagrosup EPHE IFR 128, Lyon, France.

\section{CORRESPONDENCE}

V. Cottin, Hôpital Louis Pradel, Service de Pneumologie, 28 Avenue Doyen Lepine, 69677 Lyon, France E-mail: vincent.cottin@chu-lyon.fr

\section{Received:}

March 032011

Accepted:

March 032011

First published online:

March 242011 
and qualitative HRCT analysis [3-6]. Furthermore, lung perfusion scan was significantly reduced in the upper thirds of the lungs 6 months following endoscopic treatment in 73 patients with bilateral upper lobe predominant emphysema [7]. However, no significant change was obtained in spirometry or in 6-min walk distance (6MWD) throughout. It is currently considered that bilateral partial endobronchial closure may lead to the redistribution of ventilation without genuine atelectasis and subsequently no improvement of clinical outcomes. To evaluate this hypothesis, a randomised prospective study was conducted in 20 patients with severe upper lobe predominant emphysema, who were treated with unilateral and complete endobronchial blocking devices, or with bilateral incomplete endoscopic lung volume reduction. A greater benefit was observed in patients receiving the unilateral procedure with complete occlusion of one lobe [8], and significant gain was noted in forced expiratory volume in $1 \mathrm{~s}$ (FEV1) $(+32.5 \%$ compared with $+2.5 \%$ in bilateral treatment) and $6 \mathrm{MWD}$ ( $+43 \mathrm{~m}$ and $+19 \mathrm{~m}$, respectively). Thus, unilateral treatment with complete endobronchial occlusion appears to be a better choice than bilateral treatment, although with a higher risk of pneumothorax.

\section{Non-blocking devices}

These devices are also evaluated in patients with severe heterogeneous emphysema. Among these, lung volume reduction coils (PneumRx Inc., Mountain View, CA, USA) consist of a nitinol wire with preformed shape that result in parenchymal compression after their deployment in bronchi using a special introducer system. In a recent pilot study evaluating the improvement in lung volumes, $6 \mathrm{MWD}$ and quality of life were higher in patients with homogeneous than in those with predominantly heterogeneous emphysema [9]. A study investigating the efficacy of lung volume reduction using coils in patients with severe heterogeneous emphysema was presented at the ERS 2010 Congress [10]; a total of 16 patients were treated (five in one lobe and 11 in both lungs). Lung volume reduction by coils resulted in significant improvement in pulmonary function, exercise capacity and quality of life in all patients, with acceptable tolerance.

Polymeric lung volume reduction is another non-blocking technique of endoscopic lung volume reduction. This method consists of irreversible administration of a hydrogel-foam sealant in the targeted lung compartment. The air within the foam is absorbed, and the induced tissue inflammation causes subsequent remodelling, scarring and local fibrosis that is associated with volume reduction. This technique has been shown to improve lung physiology and global functionality up to 6 months following the procedure in patients with upper lobe predominant emphysema, with an acceptable safety profile [11]. Patients with COPD at Global Initiative for Chronic Obstructive Lung Disease (GOLD) stage III may experience durable improvement in lung function, symptoms and healthrelated quality of life [12].

Other minimally invasive techniques have also been developed to treat homogeneous emphysema. One of them consists of creating extra-anatomic passageways through the normal bronchial wall to allow the trapped air to escape. To keep the passageway open, drug-eluting stents are bronchoscopically introduced using a special catheter. The data from the
Exhale Airway Stents for Emphysema (EASE) trial were presented at the ERS 2010 congress [13]. In this prospective, sham-controlled study, 315 patients with severe homogeneous emphysema were divided into two groups, with 208 of them receiving the airway bypass procedure. A reduction in lung volumes was observed just after the procedure, thus showing the proof of concept for airway bypass. However, this initial benefit decreased at 6 months. Factors controlling durability and methods to extend this early success are being explored.

\section{CHEST IMAGING}

Imaging is an integral part of respiratory medicine. It allows for a noninvasive and reliable diagnostic approach, therapy guidance and monitoring of many diseases. Two main fields of growing interest were developed during the 2010 ERS Congress, namely the application of innovative imaging techniques to obstructive pulmonary disease and to pulmonary arterial hypertension.

\section{Imaging of obstructive pulmonary disease}

Parenchymal changes in obstructive pulmonary disease, COPD in particular, are most often assessed using HRCT. Novel approaches aim to identify specific phenotypes, based on the parenchymal and airways abnormalities, in order to predict individual prognosis and response to therapy. In a study by ZAGACETA et al. [14], 115 patients with mild-to-moderate COPD underwent HRCT, with subsequent analysis of distribution and severity of emphysema. Among the patients, those with emphysema at HRCT were older, more frequently males and had a lower FEV1, lower diffusing capacity of the lung for carbon monoxide $(\mathrm{DL}, \mathrm{CO})$, and a higher total lung capacity (TLC) than their counterparts without emphysema. However, no difference was found in clinical or physiological parameters according to the anatomical distribution of emphysema. When taking into account the bronchial wall thickness, patients with predominant obstruction of the airways or with predominant parenchymal destruction could be delineated into two different COPD phenotypes, e.g. COPD with predominant obstruction of the airways and COPD with predominant parenchymal destruction [14]. Patients with predominantly parenchymal destruction had significantly higher TLC and residual volume, and lower $\mathrm{DL}, \mathrm{CO}$, while those with predominantly airway disease had increased prevalence of chronic productive cough. Multivariate linear models combining TLC, residual volume, $\mathrm{DL}, \mathrm{CO}$, cough and sputum characteristics correctly assigned $90 \%$ of patients to each group [15].

Initial data from the COPDGene ${ }^{\circledR}$ cohort were presented at the Congress, in which 1,285 subjects were analysed regarding emphysema and airway disease in relation to health status measures and body mass index, airflow obstruction, dyspnoea and exercise (BODE) index [16]. After adjustment for FEV1 (expressed as \% predicted values), a 1-mm increase in bronchial wall thickness was associated with an increase of seven points in the St George's Respiratory Questionnaire total score $(p=0.03)$ and of 13.8 points in activity sub-score $(p=0.0004)$. Emphysema did not predict quality of life score in this model. Both phenotypes were significantly associated with higher BODE scores [16]. Thus, a CT measure of airways disease was associated with health status independently of the severity of airflow obstruction. These data suggest that quantitative chest 
HRCT may provide unique information regarding the phenotype of COPD.

Similarly, findings from the initial 3 yrs of follow-up of the Evaluation of COPD Longitudinally to Identify Predictive Surrogate Endpoints (ECLIPSE) study were presented, with 2,164 patients investigated [17]. A subgroup analysis demonstrated that both emphysematous changes and airway wall thickness were independently and significantly related to the level of dyspnoea among patients, even after adjustment for FEV1 \% pred [17]. The airway wall thickness was significantly related to cough and wheezing in subjects with COPD and to wheezing in subjects without COPD [18].

A late breaking abstract from the EASE trial was also presented, with CT scans performed before and after stent placement to generate extra airway passageways [19]. Lobar volume analysis of emphysema was performed to assess regional effects and patency over time. Initial volume reduction was observed in the majority of the treated lobes, with later decline of volumes and of treatment benefits associated with loss of stent patency. Improving stent patency by better placement and reducing occlusion may thus extend the potential benefit obtained from this technique.

\section{Imaging in cardiovascular disease}

Pulmonary hypertension (PH) occasionally develops in patients with advanced COPD. Although confirmation of $\mathrm{PH}$ requires right-sided heart catheterisation, imaging techniques are developed to help predict the presence and severity of $\mathrm{PH}$. In a study of 89 patients with stable COPD, the mean pulmonary arterial pressure $\left(\bar{P}_{\mathrm{pa}}\right)$ correlated better with the diameter of the main pulmonary artery $(\mathrm{r}=0.558, \mathrm{p}=0.001)$ than with arterial oxygen tension or FEV1 $(r=-0.126, p=0.297$ and $r=-0.205, p=0.127$, respectively). Thus, the simple measure of main pulmonary artery diameter measured on HRCT can be used as a predictor of severity of $\mathrm{PH}$ [20].

Cardiac magnetic resonance imaging is also increasingly evaluated for the assessment of PH. GOMBERG-MAITLAND et al. [21] calculated the inter-ventricular septum curvature as assessed by means of three-dimensional left ventricular cine imaging in 31 patients with or without $\mathrm{PH}$. In patients with $\mathrm{PH}$, the septum curvature was less pronounced, thus reflecting septal flattening, with septum curvature fluctuating throughout the cardiac cycle, thus confirming the abnormal "bouncing" motion. Furthermore, the inter-ventricular septum curvature reached negative values in patients with severe $\mathrm{PH}$, indicating a transient concave shape. However, despite such stimulating results, the noninvasive estimation of pulmonary pressure frequently underestimates or overestimates the true $\bar{P}$ pa, and therefore does not currently obviate the need to perform right heart catheterisation in patients with suspected $\mathrm{PH}$.

Evaluation of $\mathrm{PH}$ using imaging techniques might also contribute to prognosis in selected patient populations. Pulmonary arterial hypertension associated with connective tissue disease has a poor prognosis. CRAWLEY et al. [22] followed 24 patients with newly diagnosed $\mathrm{PH}$ associated with connective tissue disease for up to 26 months, during which nine patients died. Baseline magnetic resonance-derived right ventricular stroke volume index $(p=0.03)$, right ventricular ejection fraction $(p=0.028)$ and ventricular mass index $(p=0.028)$ were independent predictors of mortality. Hence, survival was shorter in patients with right ventricular stroke volume index $\left(\leqslant 28 \mathrm{~mL} \cdot \mathrm{m}^{-2}\right)$ and with right ventricular ejection fraction lower than their median value $(\leqslant 35 \%)$, and in those with ventricular mass index greater than the median value $(\geqslant 0.82)[22]$. Furthermore, the chance to predict survival in $\mathrm{PH}$ patients using magnetic resonance imaging after initiation of medication was investigated in 80 patients [23]. The right ventricular ejection fraction was assessed before and after mean $\pm S D 17 \pm 12$ months of treatment. Interestingly, change in right ventricular ejection fraction was associated with survival, while change in pulmonary vascular resistance was not $(\mathrm{p}<0.01$ and $\mathrm{p}=0.28$, respectively). Subgroup analysis further demonstrated that a decrease in right ventricular ejection fraction over time was associated with worse probability of survival $(\mathrm{p}<0.01)$ [23].

\section{DIFFUSE PARENCHYMAL LUNG DISEASES Diagnosis of idiopathic pulmonary fibrosis}

Several presentations have reported recent developments in the diagnostic approach of diffuse parenchymal lung disease and idiopathic pulmonary fibrosis (IPF) in particular [24-27]. The histopathological specimen obtained by video-assisted thoracic or surgical biopsy, with the identification of a pattern of usual interstitial pneumonia (UIP), was considered until recently the gold standard for the diagnosis of IPF. When performed, lung biopsy has been shown to have a high diagnostic yield ( $>90 \%$ of patients) with acceptable risk of complications. Importantly, technical aspects need to be taken into account for optimal diagnostic yield, such as the need to obtain deep samples (extending into the subpleural lung parenchyma), the need to sample from more than one lobe and the need to biopsy lung areas not involved by advanced honeycombing [28]. However, performing a lung biopsy may be contra-indicated by comorbidities, including advanced age or severe PH. Therefore, when performed, biopsy should be considered early in the course of the disease.

Interpretation of the lung biopsy may be challenging, however, with important inter-observer variations in up to half of the patients, especially for the differential diagnostic patterns between UIP or nonspecific interstitial pneumonia (NSIP). Significant discordance was found among pathologists [29], even if expert in lung diseases [30], thus emphasising diagnostic issues related to the histological pattern of NSIP (which can be encountered in different contexts: idiopathic, hypersensitivity pneumonitis and connective tissue disease). Of note, an international collaborative task force is currently working under the auspices of the American Thoracic Society (ATS) and the ERS on a possible revision of the current classification of idiopathic interstitial pneumonias, addressing the distinction and the frequent overlap between UIP and NSIP, and the unlikely maintenance of clinical entities with a known cause (e.g. tobacco smoking in desquamative interstitial pneumonia) in this group.

Given the progress made in lung imaging by means of HRCT, several recent studies have addressed the diagnostic accuracy of imaging to predict the diagnosis associated with a histological pattern of UIP and therefore to confirm the clinical diagnosis of IPF in a context of idiopathic diffuse parenchymal lung disease. As acknowledged in the guidelines of the British 
Thoracic Society (BTS) [31], the diagnosis of IPF can now be confidently established even without a lung biopsy [32]. Specifically, the diagnosis of IPF is very likely in a patient with a disease compatible with IPF and with significant peripheral and lower lung honeycombing at HRCT, which obviates the need of a lung biopsy in 50-70\% of patients with IPF.

New guidelines for the diagnosis and management of IPF, yet to be published, have been developed by a joint task force of the ATS, ERS, Japanese Respiratory Society (JRS) and Asociación Latinoamericana de Tórax (ALAT), and have been presented at several international congresses. These guidelines establish HRCT criteria for the diagnosis of an imaging pattern of typical UIP, compatible with UIP or incompatible with UIP, as well as histopathological criteria for the diagnosis of a biopsy pattern of typical UIP, probable UIP, or possible UIP. The combination of HRCT and histological pattern, when available, allows a diagnosis of definite IPF, probable IPF, or possible IPF. It is anticipated that the ongoing collaborative initiative will guide pulmonologists for the diagnosis of IPF with increased level of evidence and will set the stage for future pharmacological trials in the disease.

Other studies have revisited the potential usefulness of transbronchial biopsies in the diagnostic approach of diffuse parenchymal lung disease. BERBESCU et al. [33] reported that transbronchial biopsy specimens provided adequate tissue for diagnosis in 18 out of 22 patients with UIP, allowing identification of a combination of heterogeneous interstitial fibrosis, fibroblast foci and/or honeycomb changes. CASONI et al. [34] further found an increased diagnostic yield of transbronchial biopsies in patients with diffuse parenchymal lung disease using jumbo (Olympus Medical Co., Tokyo, Japan) forceps via a rigid bronchoscope (with samples measuring $2.5 \times 1.9 \mathrm{~mm}$ on average) in comparison with normal flexible forceps $(p=0.001)$. Currently, transbronchial biopsies are not recommended for the diagnosis of idiopathic interstitial pneumonia, being more helpful in the diagnosis of sarcoidosis or organising pneumonia. However, improvement in the methods of sampling and possibly new molecular morphology analysis might eventually improve the utility of this approach in the diagnostic process of diffuse parenchymal lung disease.

An original study addressed the clinical relevance of asymmetrical disease in patients with IPF [35]. Hence, although bilaterally distributed, IPF may present with asymmetrical lung lesions at imaging. This retrospective study included 32 patients compared with 64 matched controls with a typical symmetrical IPF. Asymmetry was defined by asymmetry specific ratio (most affected - least affected fibrosis score)/ (most affected + least affected fibrosis score) $>0.2$. Patients with asymmetrical IPF showed higher DL,CO capacity (mean \pm SD $52 \pm 19 \%$ versus $43 \pm 13 \%$ of pred, $p=0.009$ ), higher frequency rate of gastro-oesophageal reflux $(62.5 \%$ versus $31.3 \%, p=0.006)$, and higher frequency of acute exacerbation ( $46.9 \%$ versus $17.2 \%, p=0.004$ ) when compared with controls. The right side was more likely to be involved and matched with the preferred posture to fall asleep in $94 \%$ of cases. The disease remained asymmetrical in patients in whom follow-up was available [35]. Asymmetry of IPF might be related to loco-regional factors including gastro-oesophageal reflux and/or repeated micro-aspirations.

\section{Prognosis and treatment of IPF}

Identification of parameters that may predict prognosis in patients with IPF is of upmost importance when developing prospective controlled trials. Indeed, surrogate outcome measures associated with prognosis are welcomed when survival cannot be the primary end-point due to reasons of feasibility. The prognostic significance of both baseline forced vital capacity (FVC) level and decrease in FVC over time was confirmed in a study including 1,156 patients randomised in two clinical trials evaluating interferon- $\gamma 1 b$ (the trial was negative for the primary end-point). Correlations between FVC and other functional parameters were generally weak, though statistically significant. The minimally clinical important difference in FVC was $\sim 3 \%$, using both distribution- and anchorbased methods [36].

CHAPRON et al. [37] reported the results of a prospective, exploratory, multicentre trial using the slow release agent octreotide (30 mg every 4 weeks intramuscularly for 48 weeks) in IPF. Previous work has shown an increased number of octreotide receptors in the lung of IPF patients, as well as inhibition of the development of bleomycin-induced lung disease in mice by a somatostatin analogue. 25 patients were included, of whom 12 received octreotide injections. Treatment was associated with a slower decline in FVC $(\mathrm{p}=0.026)$ and in $D \mathrm{~L}, \mathrm{CO}(\mathrm{p}=0.01)$ at 48 weeks when compared with historical controls. Interestingly, the binding of octreotide in the lungs by scintigraphy was higher in patients with stable than in those with progressive disease, as defined by $a \geqslant 10 \%$ decrease in FVC at 48 weeks [37].

Two large and similar clinical trials (CAPACITY 1 and 2) evaluating the efficacy and safety of pirfenidone in patients with IPF were presented at the ERS 2010 Congress [38-40]. Patients were randomised either to pirfenidone $2,403 \mathrm{mg}$. day $^{-1}$, pirfenidone $1,197 \mathrm{mg} \cdot \mathrm{day}^{-1}$, or placebo for 72 weeks. The primary end-point of mean per cent change in FVC at week 72 was met in CAPACITY 2 but not in CAPACITY 1. A dose-response relationship was observed for multiple functional outcomes in CAPACITY 2 [38]. An exploratory analysis on the magnitude of the treatment effect was then conducted in the pooled population of 692 patients from both trials [39]. When compared with placebo, pirfenidone treatment was associated with a reduction in the risk of a decline in FVC of $\geqslant 10 \%$ (hazard ratio (HR) $0.70,95 \%$ CI $0.54-0.91$ ), a reduction in the risk of a decline in 6MWD of $\geqslant 50 \mathrm{~m}$ (HR 0.74, 95\% CI $0.62-0.89)$, a reduction in the risk of death or disease progression (HR 0.74, 95\% CI 0.57-0.96), and a non-statistically significant trend towards a reduction in all-cause mortality (HR 0.77, 95\% CI 0.47-1.28) [39]. Using a Cox proportional hazards model and a log rank test, a trend favouring pirfenidone was also observed in both studies for the composite end-point of death or lung transplantation, with a non-significant risk reduction in the pooled analysis (HR 0.61, 95\% CI 0.37-1.01; $p=0.054$ ) [40]. In addition, exploratory analysis of the published phase II and phase III Shionogi trials (Osaka, Japan) using pirfenidone in patients with IPF [41, 42] suggested that the magnitude of treatment effect might be greater in patients with less advanced disease (baseline FVC $>70 \%$ pred and oxygen saturation $>90 \%$ during standard walking) $[43,44]$. 


\section{Lymphangioleiomyomatosis}

An ERS task force has recently performed a systematic and extensive review of the literature on lymphangioleiomyomatosis (LAM), and has produced comprehensive guidelines for its diagnosis and management, which were presented at the Congress. Advances with these guidelines are the proposed criteria for the diagnosis of LAM [45], which is now considered as definite in the presence of: 1) characteristic HRCT lung changes and 2) lung biopsy fitting the pathological criteria for LAM (angiomyolipoma of the kidney, thoracic or abdominal chylous effusion, lymphangioleiomyoma or lymph node pathologically involved by LAM). Characteristic HRCT findings are multiple $(>10)$ thin-walled, round, well-defined, airfilled, evenly distributed pulmonary cysts, 2-5 $\mathrm{mm}$ in diameter and up to $30 \mathrm{~mm}$. Criteria for the diagnosis of probable or possible LAM were also provided [45]. These criteria are the basis on which robust therapeutic evidence are being built by ad hoc trials. A joint task force of the ATS and the ERS will further elaborate recommendations. Finally, the serum level of vascular endothelial growth factor-D $>800 \mathrm{mg} \cdot \mathrm{mL}^{-1}$ may also contribute to the diagnosis of LAM, with a reported sensitivity of $\sim 70 \%$ and excellent specificity [46-48]. However, whether this biomarker significantly obviates the need of a videoassisted lung biopsy in patients with suspected LAM remains to be demonstrated.

\section{REHABILITATION AND CHRONIC CARE}

Five abstracts presented at the ERS 2010 Congress by young scientists, selected by group 1.2 reviewers and awarded the "best abstract 2010", were representative of the updated and relevant topics in the area of rehabilitation and chronic care. These included new approaches to rehabilitation, prescription of exercise, monitoring of activities of daily living and hydrotherapy as a mode of delivery rehabilitation to respiratory patients. One extra contribution to the body of literature around rehabilitation examined the effectiveness of careful titration of supplemental oxygen prior to a course of rehabilitation in patients who had documented desaturation (F. Dyer, Surrey Primary Care Trust, Chertsey, UK; personal communication).

Two studies explored the assessment of strength and the use of the incremental shuttle walking test to prescribe an effective training programme in patients with COPD [49, 50]. It is increasingly acknowledged that the assessment of strength is important as it can predict survival in these patients. The gold standard of quadriceps strength assessment is to use either an isokinetic dynamometer or a strain gauge to record the maximum voluntary contraction. However, this equipment is expensive and difficult to use, and therefore has a limited reliability in real life. KELLY et al. [49] compared a handheld dynamometer in 43 patients with COPD, either sitting upright with a strain gauge at 45 degrees or in a reclined position. In the Bland-Altman comparison, mean bias and confidence intervals were smaller in the reclined compared with upright position $(0.39,95 \%$ CI $-8-9$ versus $2.58,95 \%$ CI -13-18). Overall, the handheld dynamometer tended to underestimate quadriceps strength, particularly in stronger patients. However, it is likely that a significant proportion of patients presenting for rehabilitation will have reduced quadriceps strength and this portable device will suffice; indeed, it is an easy portable and reliable method to measure voluntary contraction of quadriceps muscle. Reliability may in part be related to the strength of the tester, although this was not documented in the study [49].

The study by ZAINULDIN et al. [50] looked at prescribing a specific walking programme from the incremental shuttle walking test in a COPD population. The authors prescribed the intensity of walking in terms of oxygen consumption, with the hope that the peak oxygen consumption $\left(V^{\prime} \mathrm{O}_{2}\right)$ would be $>50 \%$ of predicted values (a level normally below that recommended in international guidelines). 22 participants with relatively wellpreserved spirometry (mean FEV1 62\% pred) completed two incremental shuttle tests as recommended, followed by a further walking performance at $70 \%$ of the best speed achieved during the preliminary tests. Breath-by-breath values of metabolic parameters were measured continuously during shuttle courses with subjects wearing a lightweight portable gas analyser (Cosmed K4b2; Cosmed, Rome, Italy). The best value of the mean peak $V^{\prime} \mathrm{O}_{2}$ recorded was $1,297 \pm 315 \mathrm{~mL} \cdot \mathrm{min}^{-1}$, while the corresponding value at the 10 -min walk was $956 \pm 201 \mathrm{~mL} \cdot \mathrm{min}^{-1}$, which represents $75 \% \pm 10 \%$ of the peak $V^{\prime} \mathrm{O}_{2}$ (range $54-90 \%$ ); all the patients reached steady state exercise within 2-3 min of walking. This study concluded that training could be prescribed effectively based on performance at the incremental shuttle test; walking is an attractive form of training as it is both easy to perform and to apply as part of a home training programme.

Metabolic demand of daily tasks is an important field to explore in respiratory patients. 97 subjects with COPD $(64 \pm 9$ yrs, body mass index $25 \pm 5 \mathrm{~kg} \cdot \mathrm{m}^{-2}$, FEV1 $47 \pm 15 \%$ pred) were studied using a metabolic cart during five consecutive activities of daily living (dressing, folding towels, putting away groceries, washing up dishes and sweeping the floor) with 4-min rest between each [51]. Patients were compared with 20 healthy matched controls and referenced against a maximal exercise test. Patients used a significantly higher proportion of their peak $V^{\prime} \mathrm{O}_{2}$ than healthy subjects during these domestic activities [51].

The delivery of rehabilitation course is conventionally landbased; however, water-based rehabilitation may be an attractive option. This may be particularly important for patients with significant comorbidities, e.g. those with disabling arthritis or obesity. The study by MCNAMARA et al. [52] randomly allocated 45 COPD participants to either active land-based or water-based exercise (three sessions per week for 8 weeks), or to a control untrained group. Those patients practicing waterbased exercise performed better incremental (mean difference $49 \mathrm{~m}$ ) and endurance (mean difference $371 \mathrm{~m}$ ) shuttle walking tests, and 6-min walking test (mean difference $65 \mathrm{~m}$ ). In addition, patients in the water-based group achieved $>4$ points increase in the St George's Respiratory Questionnaire [52]. Although it was a small pilot study, the data hints at the value of water-based exercise for patients who find conventional training on land quite challenging.

Finally, another study dealt with the use of supplemental oxygen for patients who desaturate during a standard walking test performed in basal conditions (F. Dyer, Surrey Primary Care Trust, Chertsey, UK; personal communication). Ambulatory oxygen may improve the effectiveness of pulmonary rehabilitation in selected patients. All participants (predominantly 
individuals with COPD) were randomly allocated to receive oxygen, but uniquely had the flow rate carefully titrated to correct the desaturation at the time of the initial assessment, and then proceeded to active training with the appropriate oxygen flow $\left(\leqslant 6 \mathrm{~L} \cdot \mathrm{min}^{-1}\right)$. The primary outcome was the endurance shuttle walking test. 51 patients completed the study; participants using oxygen during the programme secured a significant improvement in endurance shuttle at baseline and they further increased performance by the end of rehabilitation course (F. Dyer, Surrey Primary Care Trust, Chertsey, UK; personal communication). Thus, a careful selection and titration of oxygen requirements may favourably influence the outcome of rehabilitation.

\section{GENERAL PRACTICE AND PRIMARY CARE}

Recent developments in the field of general practice and primary care are geared towards improving the timing and quality of respiratory diagnosis in primary care, the use of telemedicine tools in clinical practice and moving towards a more integrated approach of chronic conditions, including phenotyping and the management of comorbidities in daily practice. Several studies on these topics drew considerable attention at the 2010 ERS Congress.

\section{Early diagnosis of diseases of the airways}

BARNE et al. [53] investigated barriers to the use of spirometry for diagnosing asthma and COPD in 541 primary care Indian physicians. Besides the cost of purchasing a spirometer, the lack of time, lack of trained technicians and the misplaced beliefs that spirometry is a difficult test to perform and interpret were the major reasons for the underuse of this tool [53]. In Greece, Minas et al. [54] investigated the yield of a casefinding versus a screening programme in a network of trained primary care physicians. The number of subjects tested to diagnose one patient with COPD was 3.6 in the case-finding (prevalence $27.9 \%$; $€ 102$ per new diagnosis of COPD) compared with 11.9 in the screening programme (prevalence 8.4\%; $€ 173$ per new diagnosis of COPD) [54]. A case-finding programme involving primary care physicians was thus more cost-effective for the identification of new cases of COPD than a screening spirometry programme. In a large study of 305 patients from 21 centres, THORN et al. [55] further demonstrated that a handheld device measuring forced expiratory volume in $6 \mathrm{~s}$ (COPD-6) in selected patients ( $\geqslant 45 \mathrm{yrs} ; \geqslant 15$ pack-yrs) for ordinary spirometry, increased the frequency of a diagnosis of COPD from $27.2 \%$ to $73.5 \%$. Although the sensitivity and specificity of COPD-6 could be improved $(73.5 \%$ and $79.7 \%$, respectively; area under the receiver operating characteristic curve 0.800 ), its use in primary care may reduce by half the number of spirometries that do not confirm the diagnosis of COPD.

\section{Telemedicine}

Potential applications of telemedicine are manifold in the field of respiratory medicine, including the monitoring of symptoms, treatment observance and outcome of patients with COPD. JENSEN et al. [56] reported results from a web-based data capture tool used in 524 patients from 31 primary care practices; FEV1 was registered in $97 \%$ of patients, dyspnoea score in 96\%, exacerbation of COPD in 95\%, hospital admissions in $94 \%$ and smoking status in $96 \%$ of patients. The inhalation technique was evaluated in $64 \%$ of patients and the need for pulmonary rehabilitation was recorded in $76 \%$ of patients. RIKKERS-MUTSAERTS et al. [57] investigated internetbased self-management in Dutch adolescent asthmatics in a randomised controlled trial with 1-yr follow-up. It was concluded that internet-based self-management in adolescents improved asthma-related quality of life and asthma control after 3 months compared with usual care, and the effect persisted for up to 12 months. Similarly, a 6-month researcherblinded randomised trial in British patients with poorly controlled asthma (asthma control questionnaire $\geqslant 1.5$ ) demonstrated a significant improvement in asthma control compared with baseline using either mobile phone or a control paperbased diary method [58]. The use of mobile phone technology did not provide a statistically significant improvement in asthma control compared with the use of paper diaries [59]. Interestingly, in a Cochrane systematic review, McLEAN et al. [59] found that tele-healthcare interventions for asthma did not improve the quality of life in asthmatics (mean difference in asthma quality of life questionnaire, $0.04 ; 95 \%$ CI $-0.07-0.15$ ) and resulted in a non-significant increase in emergency department visits over a 12-month period (odds ratio (OR) 1.20, 95\% CI 0.59 2.44). However, there was a significant reduction in the number of hospitalisations over a 12-month period in patients using telehealthcare interventions (OR 0.29, 95\% CI 0.11-0.73) [59]. It should be noted that published studies included in this systematic review often used older technologies, which are less likely to improve health outcomes in patients with relatively mild disease, but which may nevertheless have a role in those with more severe disease who are at higher risk of hospital admission.

KRUIS et al. [60] reported on a Dutch primary care controlled clinical trial and implementation programme, which integrated COPD management improved and sustained health status and exercise capacity in primary care during 2 yrs of follow-up. Improvement in health status was consistently higher in patients with baseline Medical Research Council dyspnoea score $>2$. Improvement in exercise capacity was higher in patients with $6 \mathrm{MWD}<400 \mathrm{~m}$ at baseline and seemed to occur earlier in patients with Medical Research Council dyspnoea score $>2$ [60].

\section{Comorbidities and phenotyping}

MENÉNDEZ et al. [61] investigated the clinical profile of 3,183 COPD patients in 128 Spanish primary healthcare facilities. The mean age was $70.6 \mathrm{yrs}$ with $75 \%$ of patients older than $65 \mathrm{yrs}$, the mean (range) number of associated chronic diseases per patient was 3.9 (3.8-4.0), with the most frequent comorbidities being cardiac failure and chronic liver disease. BRUSSELLE et al. [62] demonstrated that the presence of at least three comorbidities in patients with COPD was associated with clinically meaningful worsening of health status scores. Cognitive ability test results were significantly poorer and St George's Respiratory questionnaire and health survey short form (SF)-12 physical components were significantly worse in patients with cardiovascular comorbidities. Overall, these studies demonstrate the frequency of comorbidities in primary care patients with COPD, with a high impact on overall health status and quality of life. 
PUHAN et al. [63] conducted two linked prospective cohort studies with 413 COPD patients (GOLD stages II-IV, median age 66 yrs) from 30 primary care givers in Switzerland and the Netherlands [63]. The mean FEV1 was 59\% pred, with a median age, dyspnoea, airflow obstruction index of 4 (3-5 on a scale of $0-10)$ and a corresponding median risk of 3-yr mortality of 10 $15 \%$. The median (range) health status (quantified from 0 being the worst imaginable to 100 being perfect health) was 70 (55-80). Overall, $38 \%$ of patients were smokers and $54 \%$ were exsmokers; $33 \%$ had at least one mild-to-moderate exacerbation in the past year. $20 \%$ of patients had coronary heart disease and $15 \%$ had diabetes; $24 \%$ reported on regular physical exercise at enrolment; $72 \%$ had at least one long-acting bronchodilator and $59 \%$ an inhaled corticosteroid as medication [63]. This study provides interesting insights into current management practice of patients in the community with COPD, and confirms the high prevalence of comorbidities in clinical care outside of clinical trials.

HURST et al. [64] analysed the frequency of COPD exacerbations in 2,138 patients enrolled in the ECLIPSE trial. Overall, frequent exacerbations (at least two in the first yr of followup) were observed in $22 \%$ of COPD patients with GOLD stage II, $33 \%$ with stage III, and $47 \%$ with stage IV. The single best predictor of exacerbations across all GOLD stages was a history of recurrent exacerbations. In addition, the phenotype of COPD with frequent exacerbations was independently associated with a history of gastro-oesophageal reflux or heartburn, a poorer quality of life and elevated white-cell count [64]. More data from large prospective clinical trials are needed to evaluate whether specific management of patients with frequent exacerbations may allow a better control of disease and hopefully slow the rate of decline in pulmonary function.

\section{STATEMENT OF INTEREST}

Statements of interest for C. Robalo Cordeiro, E. Clini and V. Cottin can be found at www.erj.ersjournals.com/site/misc/statements.xhtml

\section{ACKNOWLEDGEMENTS}

C. Robalo Cordeiro is Chair of the Diffuse Parenchymal Lung Disease Group. S. Singh is Chair of the ERS Rehabilitation and Chronic Care Group. F.J.F. Herth is Chair of the ERS Interventional Pulmonology Group. S. Ley is Chair of the ERS Imaging Group. N.H. Chavannes is Chair of the ERS General Practice and Primary Care Group. E. Clini is Secretary of the ERS Clinical Assembly. V. Cottin is Chair of the ERS Clinical Assembly.

\section{REFERENCES}

1 Herth FJF, Gompelmann D, Ernst A, et al. Endoscopic lung volume reduction. Respiration 2010; 79: 5-13.

2 Tamm M, Ortmann M, Ferke B, et al. Bronchial valve implantation by flexible bronchoscopy in high risk patients with advanced COPD. Eur Respir J 2010; 36: Suppl. 54, 612s.

3 Wood DE, McKenna RJ Jr, Yusen RD, et al. A multicenter trial of an intrabronchial valve for treatment of severe emphysema. J Thoracic Cardiovasc Surg 2007; 133: 65-73.

4 Coxson HO, Nasute Fauerbach PV, Storness-Bliss C, et al. Computed tomography assessment of lung volume changes after bronchial valve treatment. Eur Respir J 2008; 32: 1443-1450.
5 Springmeyer SC, Bolliger CT, Waddell TK, et al. IBV Valve Pilot Trials Research Teams. Treatment of heterogeneous emphysema using the spiration IBV valves. Thorac Surg Clin 2009; 19: 247-253.

6 Sterman DH, Mehta AC, Wood DE, et al. IBV Valve US Pilot Trial Research Team. A multicenter pilot study of a bronchial valve for the treatment of severe emphysema. Respiration 2010; 79: 222-233.

7 Hutsebaut N, Tondeur M, Geltner C, et al. Pulmonary perfusion changes after bronchial valve treatment for predominant upper lobe emphysema. Eur Respir J 2010; 36: Suppl. 54, 612s.

8 Eberhardt R, Gompelmann D, Schuhmann M, et al. Unilateral vs. bilateral endoscopic lung volume reduction in patients with severe heterogeneous emphysema: A comparative randomised case study. Eur Respir J 2010; 36: Suppl. 54, 612s.

9 Herth FJF, Eberhardt R, Ernst A. Pilot study of an improved lung volume reduction coil for the treatment of emphysema. Am J Respir Crit Care Med 2009; 179: A6160.

10 Slebos DJ, Kerstjens HAM, Ernst A, et al. Bronchoscopic lung volume reduction coil treatment of severe heterogeneous emphysema. Eur Respir J 2010; 36: Suppl. 54, 612s-613s.

11 Herth FJF, Stanzel F, Magnussen H, et al. A dose ranging study of the Aeris polymeric lung volume reduction (PLVR) system in patients with advanced upper lobe predominant (ULP) emphysema. Eur Respir J 2009; 35: Suppl. 53, 305s.

12 Herth F, Eberhardt R, Stanzel F, et al. Responses to polymeric lung volume reduction (PLVR) therapy at 6 months in patients with GOLD stage III emphysema. Eur Respir J 2010; 36: Suppl. 54, 612 s.

13 Slebos DJ, Shah PL, Cardoso PFG, et al. Exhale airway stents for emphysema (EASE) trial: Proof of initial bronchoscopic lung volume reduction. Eur Respir J 2010; 36: Suppl. 54, 375s-376s.

14 Zagaceta J, Bastarrika G, Saiz R, et al. Impact of emphysema on the clinical presentation of mild to moderate COPD. Eur Respir J 2010; 36: Suppl. 54, 176s-177s.

15 Camiciottoli G, Bigazzi F, Paoletti M, et al. Clinical identification of CT-determined COPD phenotypes. Eur Respir J 2010; 36: Suppl. 54, $45 \mathrm{~s}$.

16 Han M, Washko G, Dransfield M, et al. CT phenotype correlates with health status and BODE in COPD. Eur Respir J 2010; 36: Suppl. 54, 1012s.

17 Vestbo J, on behalf of the ECLIPSE steering committee, scientific committee and investigators. Phenotypes and biomarkers: initial 3-year findings from the ECLIPSE study - Introduction. Eur Respir J 2010; 36: Suppl. 54, 1043s.

18 Grydeland TB, Dirksen A, Coxson HO, et al. Quantitative computed tomography measures of emphysema and airway wall thickness are related to respiratory symptoms. Am J Respir Crit Care Med 2010; 181: 353-359.

19 Shah P, Slebos DJ, Cardoso PFG, et al. Late breaking abstract: EXHALE airway stents for emphysema (EASE) trial: CT analysis shows stent-based regional changes mediate early benefit \& later loss. Eur Respir J 2010; 36: Suppl. 54, 969s.

20 Park SW, Park JS, Jang AS, et al. Volumetric CT emphysema quantification for predicting pulmonary hypertension in patients with moderate to severe stable COPD. Eur Respir J 2010; 36: Suppl. $54,234 \mathrm{~s}-235 \mathrm{~s}$.

21 Gomberg-Maitland M, Maffessanti F, Patel A, et al. Three dimensional (3D) analysis of septal curvature from cardiac magnetic resonance images to determine pulmonary hypertension severity. Eur Respir J 2010; 36: Suppl. 54, 1023 s.

22 Crawley S, Johnson M, Peacock A. Prognostic value of right ventricular mass and function in connective tissue diseaseassociated pulmonary arterial hypertension. Eur Respir J 2010; 36: Suppl. 54, 200s.

23 van de Veerdonk M, Marcus J, Westerhof N, et al. In pulmonary hypertension changes in right ventricular ejection fraction better 
predict mortality than changes in pulmonary vascular resistance. Eur Respir J 2010; 36: Suppl. 54, 7s.

24 Fibla J, Molins L, Blanco A, et al. Prospective multicentric study to evaluate the role of video-assisted thoracoscopic lung biopsy in the diagnosis of interstitial lung disease: Evolving concepts. Eur Respir J 2010; 36: Suppl. 54, 129s.

25 Kiral H, Ceylan T, Kupeli M, et al. Does surgical lung biopsy change the diagnosis and treatment in interstitial lung diseases? Eur Respir J 2010; 36: Suppl. 54, 128s-129s.

26 Krenke K, Lange J, Peradzynska J, et al. Interstitial lung diseases in children - Clinical and pathological characteristics. Eur Respir J 2010; 36: Suppl. 54, 119s-120s.

27 Campainha S, Nogueira C, Brito C, et al. Interstitial lung diseases: Data analysis from a Portuguese respiratory reference hospital. Eur Respir J 2010; 36: Suppl. 54, 133s.

28 King TE Jr. Clinical advances in the diagnosis and therapy of the interstitial lung diseases. Am J Respir Crit Care Med 2005; 172: 268-279.

29 Lettieri CJ, Veerappan GR, Parker JM, et al. Discordance between general and pulmonary pathologists in the diagnosis of interstitial lung disease. Respir Med 2005; 99: 1425-1430.

30 Nicholson AG, Addis BJ, Bharucha $\mathrm{H}$, et al. Inter-observer variation between pathologists in diffuse parenchymal lung disease. Thorax 2004; 59: 500-505.

31 Wells AU, Hirani N. Interstitial lung disease guideline: the British Thoracic Society in collaboration with the Thoracic Society of Australia and New Zealand and the Irish Thoracic Society. Thorax 2008; 63: 1-58.

32 American Thoracic Society, European Respiratory Society. American Thoracic Society/European Respiratory Society international multidisciplinary consensus classification of the idiopathic interstitial pneumonias. Am J Respir Crit Care Med 2002; 165 : 277-304.

33 Berbescu EA, Katzenstein AL, Snow JL, et al. Transbronchial biopsy in usual interstitial pneumonia. Chest 2006; 129: 1126-1131.

34 Casoni GL, Gurioli C, Chhajed PN, et al. The value of transbronchial lung biopsy using jumbo forceps via rigid bronchoscope in diffuse lung disease. Monaldi Arch Chest Dis 2008; 69: 59-64.

35 Tcherakian C, Cottin V, Brillet PY, et al. Progression of idiopathic pulmonary fibrosis (IPF): Lessons from asymmetrical disease. Eur Respir J 2010; 36: Suppl. 54, 645s.

$36 \mathrm{du}$ Bois R, Albera C, Bradford W, et al. Percent predicted forced vital capacity (FVC) is a reliable, valid, and responsive measure of clinical status in patients with idiopathic pulmonary fibrosis (IPF). Eur Respir J 2010; 36: Suppl. 54, 646s.

37 Chapron J, Dornic Q, Debray MP, et al. Tolerance and efficacy of slow release octreotide in idiopathic pulmonary fibrosis. The FIBROSAND study. Eur Respir J 2010; 36: Suppl. 54, 42s.

38 Costabel U, Albera C, Bradford W, et al. Pirfenidone dose-response in patients with idiopathic pulmonary fibrosis (IPF): A comprehensive analysis of outcomes in CAPACITY 2. Eur Respir J 2010; 36: Suppl. 54, 41s.

39 Albera C, Bradford W, Costabel U, et al. The magnitude of pirfenidone treatment effect in patients with idiopathic pulmonary fibrosis (IPF): A pooled analysis of outcomes in the CAPACITY (CAP) studies. Eur Respir J 2010; 36: Suppl. 54, 41s-42s.

40 Valeyre D, Albera C, Bradford W, et al. The effect of treatment with pirfenidone on death or lung transplantation in patients with idiopathic pulmonary fibrosis (IPF): Analysis of outcomes in the CAPACITY (CAP) trials. Eur Respir J 2010; 36: Suppl. $54,42 \mathrm{~s}$.

41 Azuma A, Nukiwa T, Tsuboi E, et al. Double-blind, placebocontrolled trial of pirfenidone in patients with idiopathic pulmonary fibrosis. Am J Respir Crit Care Med 2005; 171: 1040-1047.
42 Taniguchi H, Ebina M, Kondoh Y, et al. Pirfenidone in idiopathic pulmonary fibrosis. Eur Respir J 2010; 35: 821-829.

43 Azuma A, Taguchi Y, Ogura T, et al. Exploratory analysis of phase III trial of pirfenidone: Most effective population in patients with idiopathic pulmonary fibrosis (IPF). Eur Respir J 2010; 36: Suppl. $54,41 \mathrm{~s}$.

44 Taguchi Y, Ebina M, Hashimoto S, et al. Extended analysis of phase III trial of pirfenidone: More pronounced effect in mild impairment of patients with idiopathic pulmonary fibrosis (IPF). Eur Respir J 2010; 36: Suppl. 54, 42s.

45 Johnson SR, Cordier JF, Lazor R, et al. European Respiratory Society guidelines for the diagnosis and management of lymphangioleiomyomatosis. Eur Respir J 2010; 35: 14-26.

46 Seyama K, Kumasaka T, Souma S, et al. Vascular endothelial growth factor-D is increased in serum of patients with lymphangioleiomyomatosis. Lymphat Res Biol 2006; 4: 143-152.

47 Glasgow CG, Avila NA, Lin JP, et al. Serum vascular endothelial growth factor-D levels in patients with lymphangioleiomyomatosis reflect lymphatic involvement. Chest 2009; 135: 1293-1300.

48 Young LR, Vandyke R, Gulleman PM, et al. Serum vascular endothelial growth factor-D prospectively distinguishes lymphangioleiomyomatosis from other diseases. Chest 2010; 138: 674-681.

49 Kelly J, Coissi G, Kemp S, et al. Comparison of handheld dynamometry with strain gauge for measuring quadriceps strength in COPD patients. Eur Respir J 2010; 36: Suppl. 54, 12s.

50 Zainuldin R, Mackey M, Alison J. Prescribing walking training intensity from the incremental shuttle walk test for people with COPD. Eur Respir J 2010; 36: Suppl. 54, 3s.

51 Vaes AW, Wouters EFM, Franssen FME, et al. Task-related oxygen uptake (VO2) during domestic activities of daily life (ADLs) in COPD patients and healthy subjects. Eur Respir J 2010; 36: Suppl. $54,2 \mathrm{~s}-3 \mathrm{~s}$.

52 McNamara RJ, Alison JA, McKenzie DK, et al. Water-based exercise in people with COPD and physical co-morbid conditions: A randomized controlled trial. Eur Respir J 2010; 36: Suppl. $54,3 \mathrm{~s}$.

53 Barne M, Singh M, Gaikwad K, et al. Reasons for underutilization of spirometry by practicing physicians in India. Eur Respir J 2010; 36: Suppl. 54, 768s.

54 Minas M, Konstantikaki V, Batavanis G, et al. Comparison of a network of primary care physicians and an open spirometry programme for the early diagnosis of COPD. Eur Respir J 2010; 36: Suppl. 54, 369s.

55 Thorn J, Tilling B, Lisspers $\mathrm{K}$, et al. Late Breaking Abstract: Improved prediction of COPD in patients at risk by lung function pre-screening in primary care. Eur Respir J 2010; 36: Suppl. 54, 137s.

56 Jensen MS, Soerensen TB, Grann O, et al. Structured follow-up of COPD patients according to guidelines in primary care - Using a web-based data capture tool. Eur Respir J 2010; 36: Suppl. 54, $764 \mathrm{~s}$.

57 Rikkers-Mutsaerts ERVM, Winters AE, Bakker MJ, et al. Internetbased self-management compared with usual care in adolescents with asthma: A randomised controlled trial. Eur Respir J 2010; 36: Suppl. 54, 984s.

58 Ryan D, Pinnock H, Amanda L, et al. Can mobile phone technology improve asthma control? A randomised trial. Eur Respir J 2010; 36: Suppl. 54, 368s.

59 McLean S, Chandler D, Liu J, et al. Telehealthcare interventions for asthma: Cochrane systematic review and meta-analysis. Eur Respir J 2010; 36: Suppl. 54, 368s.

60 Kruis AL, van Adrichem J, Erkelens MR, et al. Sustained effects of integrated COPD management on health status and exercise capacity in primary care patients. Int J Chron Obstruct Pulmon Dis 2010; 5: 407-413. 
61 Menéndez AA, Olmos LG, Navarro GM, et al. Clinical profile of chronic obstructive pulmonary diseases in primary health care. Eur Respir J 2010; 36: Suppl. 54, 999s-1000s.

62 Brusselle G, Jones PW, Perez T, et al. Relationship between comorbidities and patient-reported health status in the European Health-related Quality of Life in COPD study. Eur Respir J 2010; 36: Suppl. 54, 997s.
63 Puhan M, Siebeling L, ter Riet G Characteristics of COPD patients from primary care enrolled in a prospective multicenter cohort study, Eur Respir J 2010; 36: Suppl. 54, $439 \mathrm{~s}$.

64 Hurst JR, Vestbo J, Anzueto A, et al. Susceptibility to exacerbation in chronic obstructive pulmonary disease. N Engl J Med 2010; 363: 1128-1138. 